\title{
Acidente Vascular Cerebral numa mulher jovem
}

Stroke in a young woman

A doença de Moyamoya é uma doença cerebrovascular crónica e progressiva, mais comum na população asiática, caracterizada por estenose bilateral das artérias que rodeiam o círculo de Willis, com proeminente circulação colate$\mathrm{ral}^{1,2}$. É uma causa rara de AVC no jovem, com uma incidência de 0.086 por 100000 nos países ocidentais ${ }^{3}$, de etiologia desconhecida, com predomínio de apresentação isquémica nas crianças e hemorragia nos adultos ${ }^{1,4}$. Pode estar associada a várias patologias, como doenças auto-imunes e genéticas, sendo denominada nesse caso de Síndrome de Moyamoya ${ }^{1-3}$ (Tabela 1). Em 50 a 75\% dos doentes são encontrados os achados angiográficos típicos sem outra patologia associada ${ }^{1}$. Os autores apresentam o caso de uma doente de 27 anos, com antecedentes de dois eventos isquémicos aos 7 meses e 7 anos de idade, com hemiparésia esquerda sequelar, seguida em Pediatria por suspeita de doença de Moyamoya, mas sem acompanhamento em idade adulta, que recorre ao Serviço de Urgência por diminuição da força muscular no hemicorpo direito com duração de 20 minutos, tendo sido internada no serviço de Neurologia com o diagnóstico de AIT. Realizou angiografia clássica, o exame gold standard no diagnóstico desta patologia ${ }^{1-3}$, que revelou alterações típicas de Moyamoya (Figuras 1 e 2). Realizou ainda vários exames complementares de diagnóstico, não sendo encontradas patologias associadas. Não existe cura para esta patologia, o tratamento baseia-se em formas de prevenção secundária: antiagregação, não existindo dados seguros da sua eficáciaª ${ }^{2}$ e técnicas de revascularização cirúrgica, através de métodos directos (bypass) e indirectos (criação de uma maior rede de vasos colaterais), na tentativa de melhorar a perfusão cerebral ${ }^{1,2,4}$ A doente mantém seguimento em consulta de Neurologia e estão a ser discutidas as opções terapêuticas. Salientamos a raridade e a escassa experiência com esta patologia, que deve fazer parte do diagnóstico diferencial do Acidente Vascular Cerebral no jovem.

Tabela 1. Principais condições associadas à doença de Moyamoya.

\begin{tabular}{|c|}
\hline Anemia de células falciformes \\
Neurofibromatose tipo 1 \\
Síndrome de Down \\
Radioterapia da base do crânio \\
Anomalia cardíaca congénita \\
Estenose da artéria renal \\
Hemangiomas cervico-faciais gigantes \\
Hipertiroidismo \\
\hline
\end{tabular}

\section{Bibliografía}

1. Scott RM, Smith, ER. Moyamoya disease and Moyamoya syndrome. N Engl J Med 2009; 360: 1226-37

2. Takahashi J, Miyamoto S. Moyamoya disease: Recent progress and outlook. Neurol Med Chir (Tokio) 2010; 50: 824-32

3. Roach ES, et al. Management of Stroke in Infants and Children. Stroke 2008;39: 2644-91

4. Kraemer M, Heienbrok W, Berlit P. Moyamoya disease in Europeans. Stroke 2008;39: 3193-200

\section{Diagnóstico: Doença de Moyamoya}

\section{Tatiana Rodrigues ${ }^{1}$, Gustavo Cordeiro ${ }^{2}$}

${ }^{1}$ Serviço de Medicina, Centro Hospitalar do Baixo Vouga - Aveiro

${ }^{2}$ Serviço de Neurologia, Centro Hospitalar e Universitário de Coimbra
Figura 1. Angiografia da artéria carótida interna direita. Estenose distal da artéria carótida interna direita, estenose do segmento M1 da artéria cerebral média direita e estenose proximal da artéria cerebral anterior, dependendo a circulação de ramos colaterais leptomeníngeos.

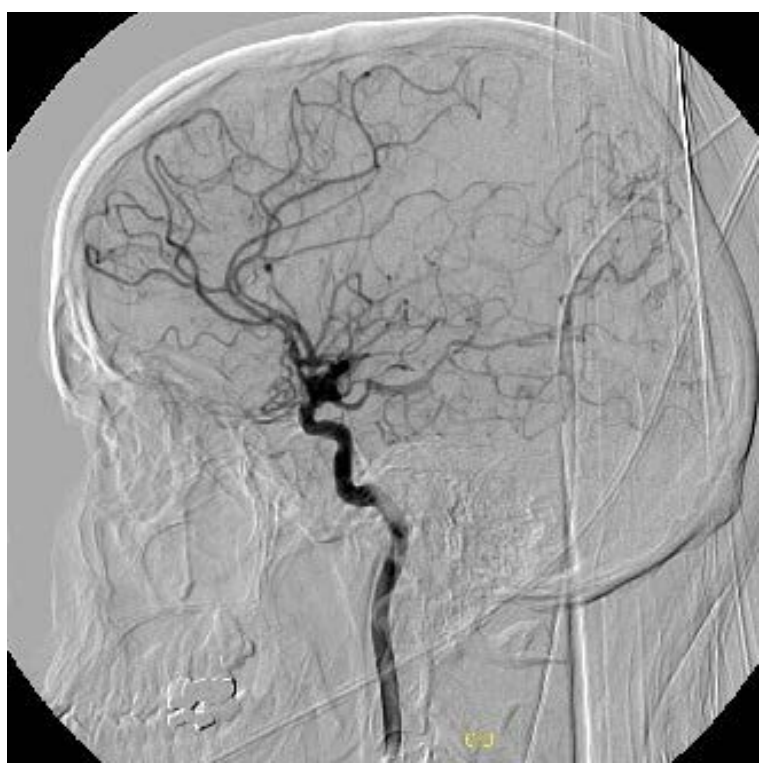

Figura 2. Angiografia da artéria carótida esquerda. Oclusão da artéria carótida interna esquerda distal, com vascularização anómala nos gânglios da base.

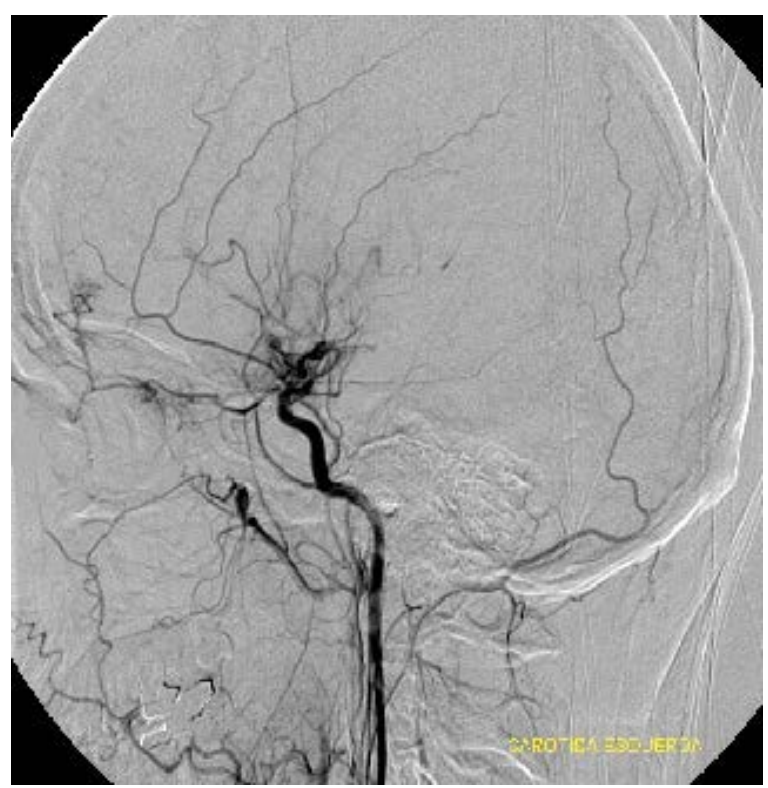

Correspondencia: regitatirodrigues@hotmail.com

Como citar este artículo: RodriguesT, Cordeiro $G$

Acidente Vascular Cerebral numa mulher jovem. Galicia Clin 2014; 75 (4): 203

Recibido: 23/03/2014; Aceptado: 06/06/2014 